\title{
Restless legs syndrome
}

\author{
Authors: Lisa Klingelhoefer, ${ }^{A}$ Kalyan Bhattacharya ${ }^{B}$ and Heinz Reichmann ${ }^{C}$
}

Restless legs syndrome (RLS), also known as Willis-Ekbom disease (WED), is a common movement disorder characterised by an uncontrollable urge to move because of uncomfortable, sometimes painful sensations in the legs with a diurnal variation and a release with movement. The pathophysiology is only partially known and a genetic component together with dopaminergic and brain iron dysregulation plays an important role. Secondary causes for RLS need to be excluded. Treatment depends on the severity and frequency of RLS symptoms, comprises non-pharmacological (eg lifestyle changes) and pharmacological interventions (eg dopaminergic medication, alpha-2-delta calcium channel ligands, opioids) and relieves symptoms only. Augmentation is the main complication of long-term dopaminergic treatment of RLS. This article will provide a clinically useful overview of RLS with provision of diagnostic criteria, differential diagnoses, possible investigations and different treatment strategies with their associated complications.

\section{Definition and diagnostic criteria}

Restless legs syndrome (RLS), also known as Willis-Ekbom disease (WED), is a common neurological movement disorder characterised by an uncontrollable urge to move (mainly the legs). ${ }^{1}$ Diagnosis of RLS is based primarily on the patient's history and on a neurological examination to exclude differential diagnoses. The diagnosis can be made if all of the following five criteria are met (International RLS Study Group (IRLSSG) diagnostic criteria): ${ }^{2}$

1 A need to move the legs usually accompanied or caused by uncomfortable, unpleasant sensations in the legs.

2 Symptoms are exclusively present or worsen during times of inactivity/rest.

3 Partial or total relief of symptoms by movement, such as walking or stretching, at least as long as the activity continues.

4 Symptoms are generally worse or exclusively occur in the evening or during the night.

Authors: ${ }^{\text {}}$ research and clinical fellow, Technical University Dresden, Dresden, Germany; ${ }^{\text {B }}$ professor, Bangur Institute of Neurology, Kolkata, India; ' professor, Technical University Dresden, Dresden, Germany
5 The occurrence of the first four essential criteria must not be solely accounted for as symptoms primary to another medical or a behavioural condition.

A single standard question for rapid screening of RLS has been validated by the IRLSSG, ${ }^{3}$ which is: 'when you try to relax in the evening or sleep at night, do you ever have unpleasant, restless feelings in your legs that can be relieved by walking or movement?' This question can be used to effectively screen large patient groups as it has $100 \%$ sensitivity and $96.8 \%$ specificity for the diagnosis of RLS. However, the final diagnosis should always be confirmed by matching the patient's history and symptoms with the IRLSSG diagnostic criteria, accompanied by an exclusion of secondary conditions.

\section{Aetiology and differential diagnoses}

The aetiology of RLS can be categorised as primary (idiopathic) or secondary. The majority of cases are primary

\section{Key points}

Restless legs syndrome (RLS) is a common neurological movement disorder, characterised by an uncontrollable urge to move the legs combined with an uncomfortable sensation in the legs.

Diagnosis of RLS is mainly based on history and physical examination, but laboratory tests are essential to rule out secondary RLS and differential diagnosis as demanded in the fifth criterion of the International RLS Study Group diagnostic criteria.

Treatment depends on the severity and frequency of RLS symptoms, comprises non-pharmacological and pharmacological interventions to relieve symptoms only and needs to be tailored to the patient, taking into account age, comorbidities and co-medication.

Dopaminergic medication, alpha-2-delta calcium channel ligands and opioids are commonly used for treatment.

Augmentation is the main complication of long-term dopaminergic treatment of RLS.

KEYWORDS: Restless legs syndrome, RLS, Willis-Ekbom disease, WED, treatment, side effects 
with unknown origin, affecting middle-aged individuals in a progressive clinical manner. The pathophysiology is partially known and includes a genetic component; six different genes (BTBD9, MEIS1, PTPRD, MAP2K5, SKOR1, TOX3) play an important role, along with dopaminergic and brain iron dysregulation. ${ }^{4,5}$ There are several reports of RLS occurring in families, which suggest an autosomal dominant mode of inheritance with variable expression and possible anticipation as there was evidence for an earlier age at onset in later generations. $^{6-8}$

Secondary RLS occurs as a result of certain conditions and the three major reversible causes are iron deficiency anaemia, pregnancy and end-stage renal disease. ${ }^{9,10}$ Other secondary causes include vitamin B12/folate deficiency, peripheral neuropathy (associated with diabetes mellitus), rheumatoid arthritis, spinal disorders such as spinal nerve root irritation, Parkinson's disease, fibromyalgia, spinocerebellar ataxia (particularly SCA 3) and Charcot-Marie-Tooth disease (type 2). For differential diagnoses, the following symptoms or diseases should be considered: nocturnal leg cramps, volitional movements such as positional discomfort or habitual foot tapping, painful legs/moving toes syndrome, akathisia, myalgia, vascular disease (eg varicose veins, venous stasis, leg oedema or deep vein thrombosis), intermittent claudication (vascular/neurogenic), arthritis and drug-induced RLS.

\section{Investigations}

Diagnosis of RLS is based primarily on the patient's history and neurological examination, which should be normal, and it is important to exclude peripheral nervous system and vascular causes. If peripheral neuropathy is suspected, an electrophysiological examination should be considered electromyography and nerve conduction studies are normal in RLS patients. Recommended blood tests are summarised in Box $1 .{ }^{11}$ Levodopa in a test dose can be used as a clinical 'challenge test' for RLS diagnosis. ${ }^{12}$ Patients with severe RLS and insomnia may require sleep studies such as polysomnography or immobilisation tests in specialised centres.

\section{Treatment}

Treatment depends on the severity and frequency of RLS symptoms, which can be assessed with the help of the RLS severity scale; this scores disease burden from mild to very severe. ${ }^{13}$ Mild RLS may be managed with reassurance

Box 1. Recommended blood tests to rule out
secondary RLS
> iron studies (specifically serum ferritin level)
$>$ full blood count (to exclude anaemia)
$>$ serum vitamin B12 and folic acid
$>$ serum glucose and HbA1C
$>$ urea and electrolytes
$>$ serum creatinine
$>$ thyroid function tests

and lifestyle changes, whereas severe RLS may require drug therapy.

First of all, secondary causes and exacerbating factors should be identified and corrected, for example:

$>$ iron supplementation for anaemia (low serum ferritin levels $(<50 \mu \mathrm{g} / \mathrm{L})$; ferritin needs to be rechecked after iron supplementation)

$>$ concomitant medications that can induce RLS symptoms or worsen (antidepressants, neuroleptics, beta-blockers, dopamine antagonists, anti-nausea drugs, antihistamines, anticonvulsants, L-thyroxine, lithium). ${ }^{14}$

Non-pharmacological interventions involve lifestyle changes (eg avoid high intake of caffeine or alcohol before bedtime) and sleep hygiene (eg sleep in a quiet, comfortable, cool environment, and keep regular bed and wake hours). Furthermore, advice for behavioural strategies during an attack may enable a patient to cope with the RLS symptoms, eg walking and stretching, massaging the affected limbs, bathing in hot or cold water, relaxation exercises (biofeedback or yoga) and distracting the mind.

Pharmacological treatment should be used in a step-bystep approach considering patient age and concomitant diseases. It is only required when the symptoms are clinically significant with impairment of night-time sleep, daytime alertness and quality of life, which occurs in about $10-15 \%$ of RLS patients. ${ }^{15,16}$ As the pharmacological treatment only targets symptoms and is not preventive and as RLS is a chronic disorder, it is likely that once the patient starts, the treatment will be lifelong. Table 1 summarises the recommended pharmacological treatment options. ${ }^{11,17-22}$ In general, the dosage should be kept as low as possible and should be administered as a single evening dose. If the patient shows intolerance to one dopamine agonist then another dopamine agonist should be tried first before levodopa or a second-line treatment.

\section{Treatment-related adverse effects}

The most common treatment-related adverse effect is augmentation. This is characterised by an overall increase in the severity of RLS symptoms like a paradoxical response to treatment: symptoms get worse with increasing dose of the medication and improve following decrease in medication. The Max Planck Institute (MPI) has defined diagnostic criteria for augmentation. ${ }^{23}$ It is the worst long-term problem of dopaminergic treatment of RLS and occurs with the use all dopaminergic agents. Augmentation is highest with levodopa and among the dopamine agonists, it is lowest with rotigotine. ${ }^{24}$ A few cases have been reported with the use of tramadol. ${ }^{14,24}$ In general, augmentation rates are lower using drugs with a longer half-life and the lowest effective dose. Low plasma ferritin levels, previous episodes of augmentation and longer treatment duration could be identified as predictors of augmentation. ${ }^{24,25}$

Early morning rebound means a reappearance of RLS symptoms in the morning as medication effects are wearing off. It occurs more frequently with short half-life medication, such as levodopa. ${ }^{26}$ To manage this complication, the dose of the currently prescribed medication can be increased, the medication intake can be delayed or a dopaminergic medication with a longer half-life can be tried. 
Table 1. Pharmacological treatment of restless legs syndrome (RLS) with recommended dose, time to full therapeutic effect, half-life and possible adverse effects. ${ }^{11,17-22}$

\begin{tabular}{|c|c|c|c|c|c|}
\hline \multicolumn{2}{|l|}{ Medication } & $\begin{array}{l}\text { Minimum } \\
\text { starting } \\
\text { dose-maximum } \\
\text { recommended } \\
\text { dose }\end{array}$ & $\begin{array}{l}\text { Time to full } \\
\text { effect of the } \\
\text { therapeutic } \\
\text { dose }\end{array}$ & Half-life & Adverse effects \\
\hline \multicolumn{6}{|c|}{ First-line treatment: dopaminergic agents } \\
\hline \multirow[t]{3}{*}{$\begin{array}{l}\text { Non-ergot } \\
\text { dopamine } \\
\text { agonists }\end{array}$} & Ropinirole & $0.25-4.0 \mathrm{mg}$ & 4-10 days & 6 hours & $\begin{array}{l}\text { Augmentation, impulse control } \\
\text { disorder, nausea, low blood pressure, } \\
\text { dizziness, headache, nasal congestion, } \\
\text { sleepiness in susceptible patients }\end{array}$ \\
\hline & Pramipexole & $0.125-0.75 \mathrm{mg}$ & at first dose & $8-12$ hours & $\begin{array}{l}\text { Augmentation, impulse control } \\
\text { disorder, nausea, low blood pressure, } \\
\text { dizziness, headache, nasal congestion, } \\
\text { sleepiness in susceptible patients }\end{array}$ \\
\hline & $\begin{array}{l}\text { Rotigotine } \\
\text { (transdermal patch) }\end{array}$ & $1-3 \mathrm{mg} / 24$ hours & 1 week & $5-7$ hours & $\begin{array}{l}\text { Skin irritation, low risk of } \\
\text { augmentation, nausea, low blood } \\
\text { pressure, dizziness, headache, nasal } \\
\text { congestion, sleepiness in susceptible } \\
\text { patients }\end{array}$ \\
\hline $\begin{array}{l}\text { Levodopa } \\
\text { formulation* }\end{array}$ & $\begin{array}{l}\text { Levodopa / carbidopa } \\
\text { or levodopa / } \\
\text { benserazid }\end{array}$ & $\begin{array}{l}50 / 12.5 \mathrm{mg} \\
-200 / 50 \mathrm{mg}\end{array}$ & At first dose & $1.5-2$ hours & $\begin{array}{l}\text { High rates of augmentation and loss } \\
\text { of efficacy with rebound phenomena }\end{array}$ \\
\hline \multicolumn{6}{|c|}{ Second-line treatment for refractory cases } \\
\hline \multirow{2}{*}{$\begin{array}{l}\text { Alpha-2-delta } \\
\text { calcium channel } \\
\text { ligands }\end{array}$} & Pregabalin & $2-300 \mathrm{mg}$ & $3-6$ days & 10 hours & $\begin{array}{l}\text { Sleepiness, dizziness, headache, fluid } \\
\text { retention }\end{array}$ \\
\hline & Gabapentin & $300-2400 \mathrm{mg}$ & $3-6$ days & $5-7$ hours & Sleepiness, dizziness, fluid retention \\
\hline Hypnotics & Clonazepam & $0.5-2.0 \mathrm{mg}$ & $\begin{array}{l}\text { First dose: } \\
\text { effect mainly } \\
\text { on sleep }\end{array}$ & $30-40$ hours & $\begin{array}{l}\text { High risk of sleepiness, dizziness, } \\
\text { morning drug hangover }\end{array}$ \\
\hline \multirow[t]{3}{*}{ Opioids } & $\begin{array}{l}\text { Prolonged-release } \\
\text { oxycodone-naloxone }\end{array}$ & $\begin{array}{l}5.0 / 2.5 \mathrm{mg} \\
-40 / 20 \mathrm{mg} \text { twice } \\
\text { daily }\end{array}$ & 7 days & 1 hour & $\begin{array}{l}\text { Constipation, nausea, dizziness, } \\
\text { addiction and tolerance, increased } \\
\text { sleep apnea, fatigue, somnolence, } \\
\text { pruritus, dry mouth }\end{array}$ \\
\hline & Tramadol & $50-100 \mathrm{mg}$ & At first dose & $6.3 \pm 1.4$ hours & $\begin{array}{l}\text { Constipation, nausea, dizziness, } \\
\text { addiction and tolerance, increased } \\
\text { sleep apnea, fatigue, somnolence, } \\
\text { pruritus, dry mouth, augmentation }\end{array}$ \\
\hline & Methadone & $5-40 \mathrm{mg}$ & At first dose & 15-60 hours & $\begin{array}{l}\text { Constipation, fatigue, sedation, flush, } \\
\text { depression and anxiety }\end{array}$ \\
\hline
\end{tabular}

*If patients are intolerant to dopamine agonists or if symptoms are not completely controlled under dopamine agonists, levodopa has shown good short-term effects and is useful for intermittent RLS (symptoms less than three times a week) and as rescue medication.

Impulse control disorders (ICD) as an adverse effect of dopaminergic agents are well known in patients with Parkinson's disease. Despite the lower doses of dopaminergic medication used, the incidence of ICDs during RLS treatment is estimated to be between $3 \%$ and $17 \%$ and include obsessivecompulsive behaviour, hypersexuality, binge eating, pathologic gambling, punding and compulsive shopping. ${ }^{27,28}$ If ICDs appear, the dopaminergic medication needs to be reduced (or even completely stopped) until the adverse effect resolves. A non-dopaminergic treatment should be tried instead.

\section{Conclusions}

RLS is a common neurological movement disorder that can have a great impact on quality of life, mainly as a result of disturbed night-time sleep and daytime somnolence. Secondary causes need to be excluded so treatment can be tailored specifically, eg by iron supplementation. Symptomatic treatment depends on the severity and frequency of RLS symptoms and depends on age, concomitant diseases and medication. In mild RLS, reassurance and lifestyle changes 
might be sufficient, whereas in moderate to severe cases, pharmacological treatment is required.

\section{Conflicts of interest}

The authors declare no conflicts of interest.

\section{References}

1 Allen RP, Picchietti D, Hening WA et al. Restless legs syndrome: diagnostic criteria, special considerations, and epidemiology. A report from the restless legs syndrome diagnosis and epidemiology workshop at the National Institutes of Health. Sleep Med 2003;4:101-19.

2 International Restless Leg Syndrome Study Group. 2012 Revised IRLSSG diagnostic criteria for RLS. Rochester, USA: IRLSSG, 2012. Available online at http://irlssg.org/diagnostic-criteria/ [Accessed 10 May 2016].

3 Ferri R, Lanuzza B, Cosentino FI et al. A single question for the rapid screening of restless legs syndrome in the neurological clinical practice. Eur J Neurol 2007;14:1016-21.

4 Garcia-Borreguero D, Williams AM. An update on restless legs syndrome (Willis-Ekbom disease): clinical features, pathogenesis and treatment. Curr Opin Neurol 2014;27:493-501.

5 Wijemanne S, Jankovic J. Restless legs syndrome: clinical presentation diagnosis and treatment. Sleep Med 2015;16:678-90.

6 Trenkwalder C, Seidel VC, Gasser T, Oertel WH. Clinical symptoms and possible anticipation in a large kindred of familial restless legs syndrome. Mov Disord 1996;11:389-94.

7 Lazzarini A, Walters AS, Hickey K et al. Studies of penetrance and anticipation in five autosomal-dominant restless legs syndrome pedigrees. Mov Disord 1999;14:111-6.

8 Dhawan V, Ali M, Chaudhuri KR. Genetic aspects of restless legs syndrome. Postgrad Med J 2006;82:626-9.

9 Daubian-Nose P, Frank MK, Esteves AM. Sleep disorders: a review of the interface between restless legs syndrome and iron metabolism. Sleep Sci 2014;7:234-7.

10 Gupta R, Dhyani M, Kendzerska T et al. Restless legs syndrome and pregnancy: prevalence, possible pathophysiological mechanisms and treatment. Acta Neurol Scand 2016;133:320-9.

11 Klingelhoefer L, Cova I, Gupta S, Chaudhuri KR. A review of current treatment strategies for restless legs syndrome (Willis-Ekbom disease). Clin Med 2014;14:520-4.

12 Stiasny-Kolster K, Kohnen R, Moller JC, Trenkwalder C, Oertel WH. Validation of the "L-DOPA test" for diagnosis of restless legs syndrome. Mov Disord 2006;21:1333-9.

13 Walters AS, LeBrocq C, Dhar A et al. Validation of the International Restless Legs Syndrome Study Group rating scale for restless legs syndrome. Sleep Med 2003;4:121-32.

14 Hoque R, Chesson AL Jr. Pharmacologically induced/exacerbated restless legs syndrome, periodic limb movements of sleep, and REM behavior disorder/REM sleep without atonia: literature review, qualitative scoring, and comparative analysis. J Clin Sleep Med 2010;679-83.
15 Hening W, Walters AS, Allen RP et al. Impact, diagnosis and treatment of restless legs syndrome (RLS) in a primary care population: the REST (RLS epidemiology, symptoms, and treatment) primary care study. Sleep Med 2004;5237-46.

16 Stevens MS. Restless legs syndrome/Willis-Ekbom disease morbidity: burden, quality of life, cardiovascular aspects, and sleep. Sleep Med Clin 2015;10:369-73.

17 Garcia-Borreguero D, Kohnen R, Silber MH et al. The long-term treatment of restless legs syndrome/Willis-Ekbom disease: evidencebased guidelines and clinical consensus best practice guidance: a report from the International Restless Legs Syndrome Study Group. Sleep Med 2013;14:675-84

18 Garcia-Borreguero D, Ferini-Strambi L, Kohnen R et al. European guidelines on management of restless legs syndrome: report of a joint task force by the European Federation of Neurological Societies, the European Neurological Society and the European Sleep Research Society. Eur J Neurol 2012;191385-96.

19 Trenkwalder C, Benes H, Grote L et al. Prolonged release oxycodone-naloxone for treatment of severe restless legs syndrome after failure of previous treatment: a double-blind, randomised, placebo-controlled trial with an open-label extension. Lancet Neurol 2013;121141-50.

20 Lauerma H, Markkula J. Treatment of restless legs syndrome with tramadol: an open study. J Clin Psychiatry 1999;60:241-4.

21 Silver N, Allen RP, Senerth J, Earley CJ. A 10-year, longitudinal assessment of dopamine agonists and methadone in the treatment of restless legs syndrome. Sleep Med 2011;12:440-4.

22 Ondo WG. Methadone for refractory restless legs syndrome. Mov Disord 2005;20:345-8.

23 Garcia-Borreguero D, Allen RP, Kohnen R et al. Diagnostic standards for dopaminergic augmentation of restless legs syndrome: report from a World Association of Sleep Medicine-International Restless Legs Syndrome Study Group consensus conference at the Max Planck Institute. Sleep Med 2007;8:520-30.

24 Garcia-Borreguero D, Williams AM. Dopaminergic augmentation of restless legs syndrome. Sleep Med Rev 2010;14:339-46.

25 Trenkwalder C, Hogl B, Benes H, Kohnen R. Augmentation in restless legs syndrome is associated with low ferritin. Sleep Med 2008;9:572-4.

26 Guilleminault C, Cetel M, Philip P. Dopaminergic treatment of restless legs and rebound phenomenon. Neurology 1993;43:445.

27 Cornelius JR, Tippmann-Peikert M, Slocumb NL, Frerichs CF, Silber MH. Impulse control disorders with the use of dopaminergic agents in restless legs syndrome: a case-control study. Sleep 2010;33:81-7.

28 Schreglmann SR, Gantenbein AR, Eisele G, Baumann CR. Transdermal rotigotine causes impulse control disorders in patients with restless legs syndrome. Parkinsonism Relat Disord 2012;18:207-9.

Address for correspondence: Dr L Klingelhoefer, Department of Neurology, Technical University Dresden, Fetscherstraße 74, 01307 Dresden, Germany.

Email: lisa.klingelhoefer@uniklinikum-dresden.de 